\title{
A AVIDEZ DE ANTICORPOS ESPECÍFICOS ANTI-TOXOPLASMA DA CLASSE IgG E SUA UTII.IZAÇÃO NA DIFERENCIAÇÃO ENTRE TOXOPLASMOSE RECE.NTE E CRÔNICA EM CAPRINOS
}

\author{
TOXOPIASMA - SPECIFIC IRG ANTIBOIDES AVIDTY EIISA AND ITS ROLE IN THE DIFFEKLNTIATION \\ BEIWEEN RECENT AND CHRONIC TOXOPIASMOSIS IN GOATS
}

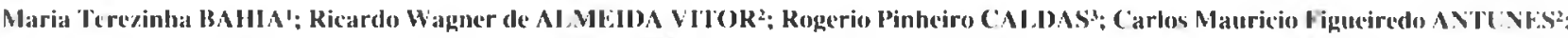
Cléa de Andrade (HIAKI²

\begin{abstract}
RESUMO
Iô avallialda a avider de anticorpos lgG como marcador sorológico de infeç̧ão recente e crônica pélo Toxoplasma gondii. altravés da dissecciação do complexo antígeno-anticorpo com uréia. A avaliação foi realizada medindo-se a percentagem de

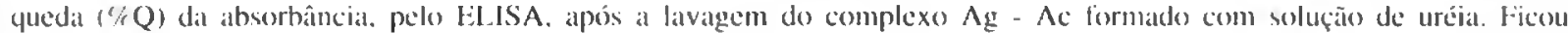
determinado que a concentração de uréia 9 Molar (M) foi at que melhor diferenciou infecçóes recentes e crônicas de cahras experimentalmente infectadals com Toxoplasma gondii. a yue a \%Q da absorbância decresce com o tempo de inleç̧̃̃o do animal, tornando-se estível em torno do I0(5 dia após a inoculação. Em um grupo de 116 amostras de soro. coletadas de caprinos naturalmente infectades, foram demonstrados perlis característicos de toxoplasmose recente, crônical ou em fase de transição. Os perfis foram previamente determinados pela avaliação da evolução dos níveis de anticorpos lgg(i pela reação de imunofluorescencia indireta. Os atnimais caracterizados como portadores de toxoplasmose crônica apresentaram uma \% $Q$ da absorbância de $26.32 \pm 10.84$. Para toxoplasmose recente a $\% Q$ dà absorbância observada foi de $77.61 \pm 13.89$ e para o perfil de transiçāo. $46.22 \pm 11.94$
\end{abstract}

UNITERMOS: Toxoplasmose; Infecções: IgGi: Caprinos

\section{IN'TRODUÇÃO}

Na toxoplasmose caprina a associação dos niveis de anticorpos da classe Ig $i$ com a lase de infecção dos animais ex extremamente dificil, mesmo em animais infectados experimentalmente ${ }^{8}$. Em infecçoes naturais. a observação dos níveis de anticorpos da classe IgG não permitem qualquer associação com a fase clínica da infecçãot ${ }^{-t}$. Sendo assim, torna-se clara a necessidade de um marcador sorológico de fase aguda, a exemplo do que ocorre na toxoplasmose humana. Para o diagnóstico da toxoplasmose aguda, sintomática ou nāo, dois tipos de marcadores sorológicos são de valor'. Um deles é representado por uma significativa ascensão dos lítulos de anticorpos da classe $\lg$ G. Outro marcador de infecção recente é a presença de imunoglobulinas da classe lgM, evidenciadas normalmente através da Reação de Imunofluorescencia Indireta (RIFI). Neste caso, resultados falso-positivos podem ocorrer nos soros contendo anticorpos antinucleares ou fator reumatóide². Reações falso-negativas são verificadas nos soros com altos títulos de anticorpos lga. Outros testes imunológicos, como os imunoenzimálicos. não sofrem as interlerências citadas acima mas, por serem nitidamente mais sensíveis, passam a detectar anticorpos lgM por períodos mais longos, o que de certo modo pode prejudicar seu significado como marcador de infecção recentc ${ }^{3}$.

Tem sido reconhecido um novo marcador sorológico, capar. de distinguir entre infecções recentes e antigas, que diz. respeito à avidez de anticorpos IgG específicos. Nas infecf̧ões recentes, uma alta percentagem desses anticorpos mostra baixil avidez aos antigenos correspondentes. Durante o transcorrer de semanas ou meses após a infecȩão, essess anticorpos vão apresentando avidez crescente, de modo que em infecçōes de mais longa duração, encontra-se um predomínio marcante de anticorpos de altat afinidade. A avaliação da avidez é baseada na dissociação dos complexos antígenoanticorpo ( $\mathrm{Ag}$ - $\mathrm{Ac}$ ) pela ação de agentes desnaturantes de proteínas ou desestabilizantes de ligaçōes de pontes de hidrogênio ${ }^{5.7}$. A utilização desta técnica como marcador de infecção recente já foi utilizada com sucesso na rubéola ${ }^{7}$ e na

\footnotetext{
- Doulor - Linversidade de Altenas-MGi

- Dentar Iniversidade Prederal de Minas (ieraiis

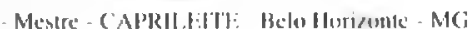




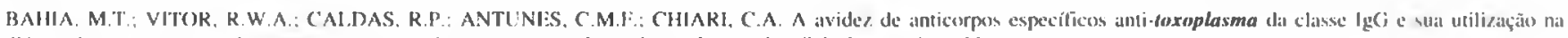

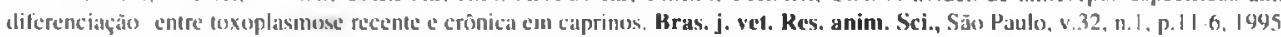

loxoplasmose humana ${ }^{3.5}$.

Fste trabalho foi realizado objetivando a avaliação da determinação da avidez de anticorpos IgG específicos como marcador sorológico de fase aguda da toxoplasmose caprina.

\section{MATERIAL E MÉTODO}

\section{Soros utilizados}

a) Soros de cinco caprinos experimentalmente infectados com a cepa C4 de Toxoplasma gondii foram coletados do 1 . ao $5(0)^{\circ}$ dia após a inoculação (DAI). A cepa C4 foi isolada do pulmão de um cão necropsiado $\mathrm{cm} 1972$ no Instituto de Medicina Tropical de São Paulo.

b) Soros de 200 caprinos normais ou naturalmente infeclados pelo Toxoplasma gondii foram selecionados pela Reação de Imunofluorescência Indireta (RIFI), realizada de acordo com CHIARI ${ }^{4}$ (1985). Os animais normais foram submetidos a uma segunda coleta, com intervalo de dois meses, com o objetivo de detectar infeç̧ão recente pelo Toxoplasma gondii. Nos animais positivos da primeira coleta, uma segunda foi realizada 5 meses depois para avaliar a evolução dos níveis de anticorpos da classe IgG. Os 116 animais positivos foram divididos em três grupos, de acordo com a cvolução dos níveis de anticorpos, seguindo os critérios utilizados para a toxoplasmose humana (perfil sorológico): (1) 23 animais que apresentaram viragem sorológica (infecção recente); (2) 20) animais cujos títulos de anticorpos apresentaram uma queda entre duas coletas (transição entre fase aguda e crôni(a); (3) 73 animais cujo título de anticorpos não variou entre duas coletas (fase crônica).

\section{'Técnica empregada}

Os soros foram ensaiados em duas séries de diluições na mesma placa, através do ELISA9 . As lavagens das placas, após a fase de incubação dos soros, foram feitas para uma das séries de diluições, com solução salina tamponada contendo Tween 20 a 0,05\% (PBST), em três períodos sucessivos de 5 min. sob agitação.

Para a outra série, as três lavagens foram feitas com PBST contendo uréia. Na quarta lavagem, realizada para as duas séries, utilizou-se PBST. A diferença entre as leituras em absorbûncia observada na segunda séric (absorbância com uréia: AU), cm relação à da primeira séric (absorbância sem urćia: A) foi expressa $\mathrm{em}$ percentagem de queda $(\% \mathrm{Q})^{3}$.

$$
\% \mathrm{Q}=100-\frac{\mathrm{AU} \times 100}{\mathrm{~A}}
$$

Para avaliar a concentração de uréia a ser empregada. foram testadas as concentraçōes de $3 \mathrm{M}, 6 \mathrm{M}$ e $9 \mathrm{M}$ em soros de 5 cabras experimentalmente infectadas pelo Toxoplasma gondii. sendo oito soros de cada animal, quatro coletados até $50 \circ$ e quatro após 200 dias de inoculação. Os soros foram ensaiados, com cada concentração de uréia, nas diluições de $1: 64,1: 256 \mathrm{c} 1: 1024$.

\section{Análise Estatística}

A relação entre o tempo de infecção (animais infectados experimentalmente) e a \%Q da absorbância foi analisada através da regressão linearo

As \%Q da absorbância obtidas nos três grupos de caprinos naturalmente infectados foram comparadas através da análise de variânciato.

\section{RESULTADOS}

As curvas médias obtidas nos ensaios realizados com diferentes concentrações de uréia e diluiçōes de soros de caprinos experimentalmente infectados pelo Toxoplasma gondii, em fases recentes e crônicas, são apresentadas na Fig. 1. Os resultados indicam que a concentração de uréia 9M e a diluição do soro de 1:64 foram as condições que melhor diferenciaram infecçōes recentes c crônicas.

As curvas mínima, média c máxima da $\% \mathrm{Q}$ da absorbância, obtidas de soros coletados do $3^{*}$ ao 50()$^{\circ} \mathrm{DAI}$ de cinco cabras experimentalmente infectadas pelo Toxoplasma gondii são apresentadas na Fig. 2. A \%Q da absorbância decresce até o 100. DAI, tornando-se estável a partir desse período. Os resultados da análise de regressão linear mostram uma correlação de Pearson significativa entre o tempo de infecção c a \%Q da absorbâncial $(r=0,8(0)$.

Para a análise dos resultados obtidos no grupo de animais naturalmente infectados foi inicialmente realizada uma comparação, por meio do teste da análise de variância, entre as duas coletas dos animais do grupo 3 (considerados crônicos). ficando demonstrado não existir diferença signilicativa entre elas $\left(F_{\mid g]}=4,42\right)$; sendo assim. para análises posteriores foi considerada a média das duas coletas do grupo 3

A comparação dos resultados obtidos na segunda coleta do grupo 2 (animais considerados portadores de toxoplasmose crônica) com os resultados da média das duas coletas do grupo 3, por meio da análise de variância, demonstrou não existir diferença significativa entre esses grupos $\left(F_{|g|}=3,26\right)$.

Considerando as análises realizadas anteriormente, os animais foram reagrupados $\mathrm{cm}$ três novas categorias: (A) animais do grupo I; (B) animais da primeira coleta do grupo 2; 


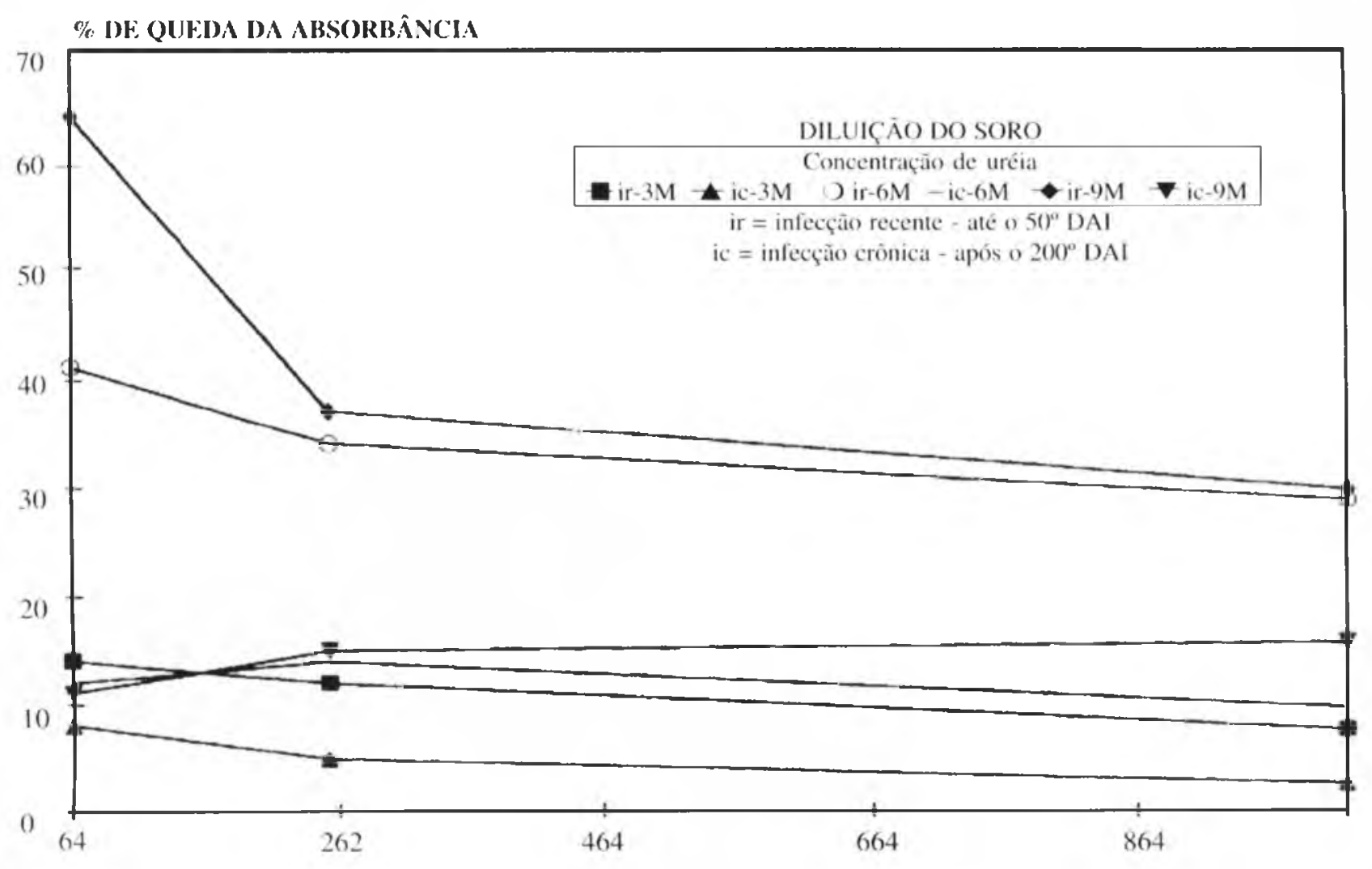

FICURA 1

Curvas médias da percentagem de queda da abvorbância a $492 \mathrm{~nm}$. pela Reação Imunoenzimática bLLSA. alpós tratamento do complexo Ag - Ac com urélia. nas concentraçōes de 3M. $6 \mathrm{M}$ e $9 \mathrm{M}$. em soros de cinco cabras experimentalmente intectadas peloToxoplasma gondii.

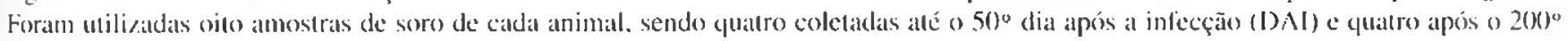
DAI.

(C) animais da segunda coleta do grupo 2 somados aos do grupo 3 (Fig.3). Fsses dados, analisados através do leste de análise de variância. evidenciaram uma diferença significativa entre as \%Q da absorbância observadass nos grupos $\mathrm{A}$. B c $C\left(F_{2 y 1}=186,84\right)$. As médias de \% $Q$ da absorbância observadas foram $77.61 \pm 1.3,89 ; 40.22 \pm 11,94 ; 26.32 \pm$ 10.84, paral os grupos A. B e C, respectivamente.

Os resultados acima, comparados anos da lïg.2, mostram que a $\% Q$ da absorbancia obtida nos soros classilicados no grupo "A" é semelhante à observada até o 5(0" 1) AI. A \%Q do grupo "B" corresponderia ao período entre o $50 "$ e o 1000 DAI eo do grupo após o $10\left(0^{\circ} \mathrm{D} \wedge \mathrm{I}\right.$ de animais inoculados experimentalmente.

\section{DISCUSSก̃O)}

A alfinidade de anticorpos IgG anti-Toxoplasma, medida em lunção da dissociação de pontes de hidrogênio, assume importância na determinação do tempo de vigência da infec- çăo por Toxoplasma gondii, podendo ser utilizada cono apoio ao diagnóstico de infeçēes recentes. läcou demonstratdo que em cabras experimentalmente infectadals. o grau de dissociação do complexo Ag - Ac vai diminuindo como tempo de infecçāo, lomando-se estável a partir do $100^{0}$ DAI. $\triangle \% Q$ da absorbância em soros provenientes de inlecęōes toxoplásmicas recentes e crônicas. observadas neste experimento, foi superior à observada em estudos sobre toxoplasmose humanis ${ }^{3}$.

Essa diferença provavelmente está relacionada à meıdologia utilizada e nāo a características dos anticorpos antiToxoplasma humanos e caprinos, pois em outro estudo sobre toxoplasmose humanar foi observado um grau de dissociação mais próximo ao observado neste trabalho. Esta variação provavelmente está relacionada com o número de lavagens do complexo Ag - Ac e com a concentração de uréia empregada nos diferentes trabalhos.

Os dados obtidos em soros de amimais naturalmente infectados 


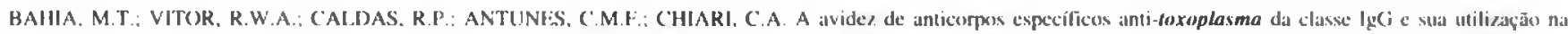

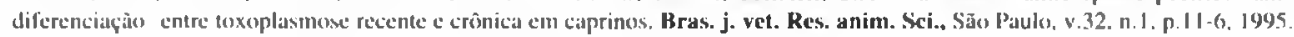

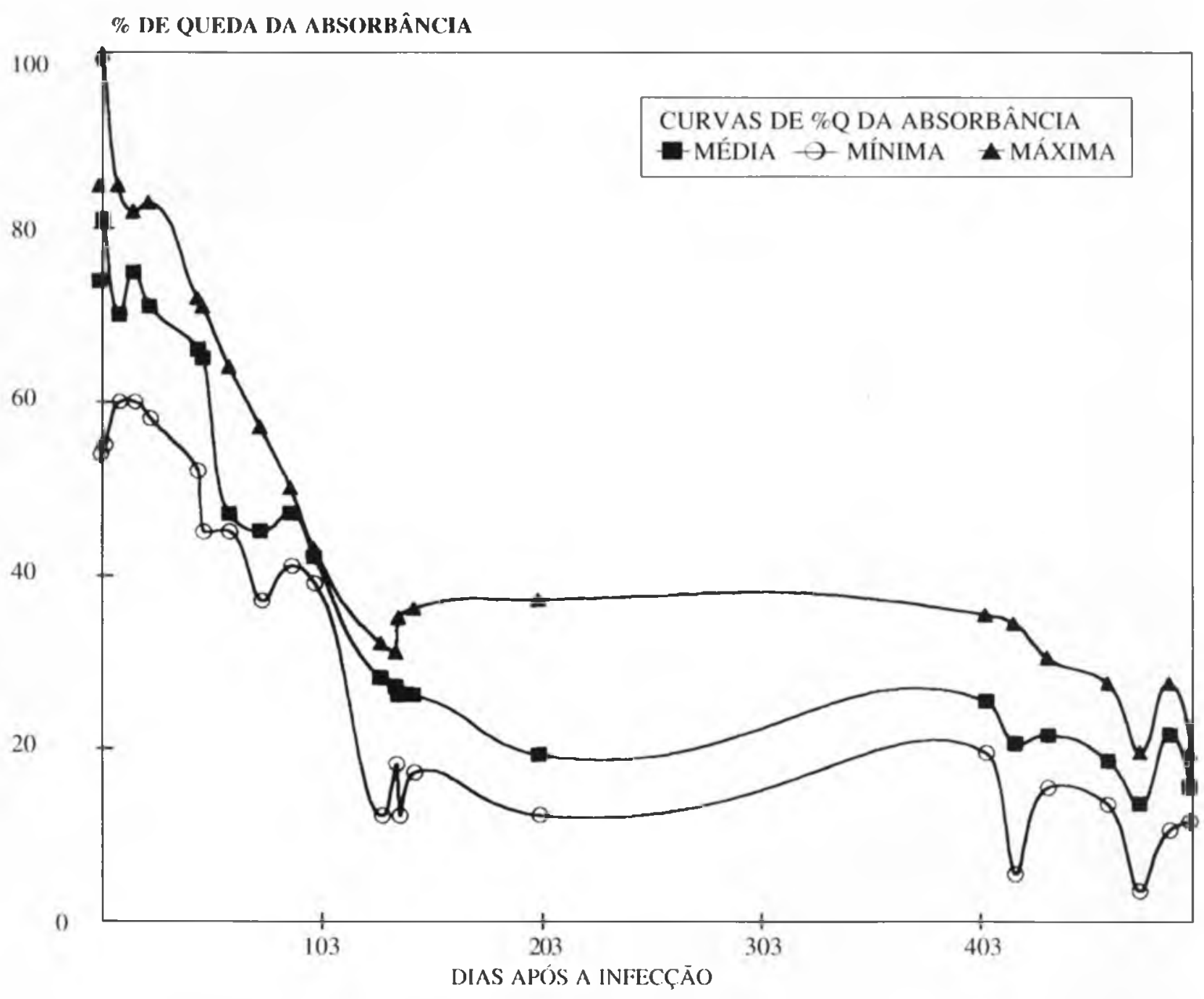

FIGURA 2

Curva média, máxima e mínima da percentagem de queda da absorbância a 492 nm, pela Reação Imunoenzimática EI ISA, após tratamento do complexo $\mathrm{Ag}$ - Ac com uréia 9M. em soros de cinco cabras experimentalmente infectadas pelo Toxoplasma gondii, coletados do $3^{\circ}$ ao $5(0)^{\circ}$ dia após a intecção.

possibilitaram melhor avaliação da técnica na toxoplasmose caprina, por permitir relacionar a evolução dos níveis de anticorpos IgG como grau de dissociação do complexo Ag - Ac. Naturalmente, a determinação de avidez de anticorpos IgG seria uma técnica auxiliar na diferenciação das fases aguda e crônica da toxoplasmose caprina mas, como não existe, atualmente, outro marcador de fase aguda padronizado para esse sistema, essa técnica assume grande importância, podendo ser empregada principalmente na obtenção de inferências em estudos populacionais e como auxiliar em diagnósticos individuais.

Requer, no entanto, estudos mais detalhados, realizados comparativamente a outros marcadores de fase aguda da infecção.

\section{CONCLUSÃO}

A determinação da avidez de anticorpos da classe IgG pode ser utilizada como método auxiliar na determinação da fase de infecção da toxoplasmose caprina, pois:

a) em infeç̧ōes experimentais looi possível demonstrar que a $\% \mathrm{Q}$ da absorbância decresce com o tempo de infeç̧ão;

b) em animais naturalmente infectados foi demonstrada relação entre a \%Q da absorbância e o "pertil sorológico do animal". 
BAllIA. M.T.: VITOR, R.W.A.; CAI.DAS, R.P.; ANTUNFS, C.M.F.; CHIARI. C.A. A avide» de anticurpos específicos anti-toxoplasma da classe lgGi e sua utilizaçüı na diferenciaçāo entre toxoplasmose recente e crônica tem caprinos. Bras. j. vet. Res. anim. Sci., Sāo Paulo. v. 32, n.1. p.11-6, 1995.

\section{\% DE QUEDA DA ABSORBÂNCIA}

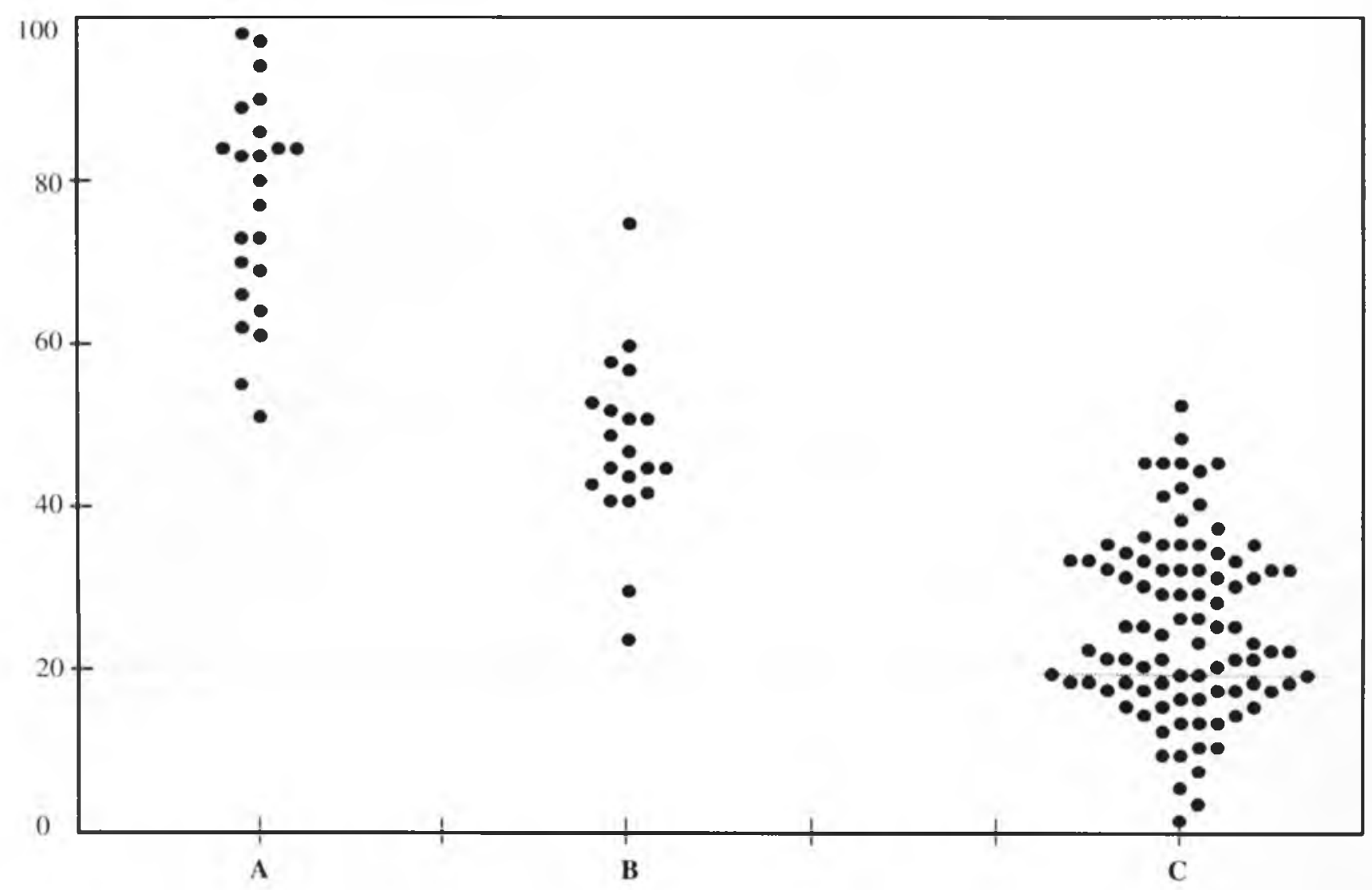

GRUPOS DE ANIMAIS

FIGURA 3

Resultados da percentagen de queda da absorbância a 492 nm, pela Reação Imunoenzimática ELISA. após tratamento do complexo AgAc com uréia $9 \mathrm{M} . \mathrm{cm}$ soros de caprinos natturalmente infectados pelo Toxoplasma gondii. O grupo A representa os animais com perfil sorológico característico de toxoplasmose recente. No grupo C estão representados os caprinos com perfil de toxoplasmose crônica e no) grupo B os com perfil de transição.

\section{AGRADECIMENTOS}

Ao professor Paul Williams pela revisão do texto em inglês.

À sra. Rosálida Estevam Nazar Lopes e ao sr. José Luiz de Faria pelo auxílio técnico. 


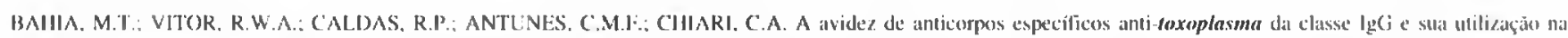

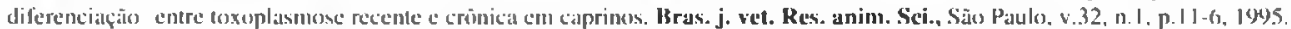

\section{SUMMARY}

For serological characterization of recent Toxoplasma infection in goats low avidity lgCi specific antibodies were studied. Avidity was evaluated as the decrease of absorbance in EL ISA test after treating plates with 3,6 and $9 \mathrm{M}$ ureal, als a dissociating solution of low avidity antigen-antibody complexes. A concentration of $9 \mathrm{M}$ urea best discriminated between recent and old infections in goats experimentally infected with Toxoplasma gondii. Absorbance after treating plates with $9 \mathrm{M}$ urea decreased in relation to the duration of infection. levelling off about the $100^{\text {th }}$ day after inoculation. In a group of 116 serum samples from naturally infected goats patterns of recent. transitional or chronic Ioxoplasmosis were demonstralled. Serological patterns were previously determined by immunofluorescent assay. For chronic loxoplasmosis infection. the observed decrease of absorbance was $26.32 \pm 10.84$. For recent toxoplasmosis it was $77.61 \pm 13.89$, and for transitional pattern. $46.22 \pm 11.94$.

UNITERMS: Toxoplasmosis; $\operatorname{lgG}$; Infections; Goats

\section{REFERÊNCIAS BIBLIOGRÁFICAS}

01 - CAMARGO, M.E.; FERREIRA. A.W. O laboratório no diagnóstico da toxoplasmose. Laes-Haes, v. 61, p. 44-56. 1989.

02 - CAMARGO, M.E.; LESER.P.G.; ROCCA, A. Rheumatoid factors as a cause for false positive IgM antitoxoplasma fluorescence tests. A technique for specific results. Revista do Instituto de Medicina Tropical de São Paulo, v.14, p.310-3, 1972.

03 - CAMARGO, M.E.; SILVA, S.M.: LESER, P.G.; GRANATO, G.II. Avidez de anticorpos IgG específicos como marcador de in feç̧ão primária recente pelo Toxoplasma gondii. Revista do Instituto de Medicina Tropical de São Paulo. v.33, p.213-8, 1991.

(04 - CHIARI, C.A.; LIMA, J.D.; ANTUNES, C.M.F. Reações de Imunofluorescência Indireta e de Sabin-Feldman na pesquisa de anticorpos anti-Toxoplasma gondii em soros caprinos. Arquivo Brasileiro de Medicina Veterinária e Zootecnia, v.37, p.121-9, 1985.

(15 - HEI.DMAN, K.; LAPPALAINEN. M.: SEPPAIA, L.; MAKAl:LA, O. Recent primary Toxoplasma infection indicaled by low avidity of specific IgG.Journal of Infections Diseases, v.15\%, p.736-40, 1989.
06 - SNEDECOR, G.M.; COCHRAN. W.G. Statistical methods. 7.ed. Ames, The lowa State University Press, 1985.

(07 - THOMAS, H.T.J.; MORGAN-CAPNER. P. Ruhellaspecific IgG subclass avidity ELISA and its role in the differentiation between primary rubella and rubclla reinfection. Epidemiological Infection, v.101, p. 591-8. 1988.

08 - VITOR, R.W.A. Infecção experimental de caprinos pelo Toxoplasma gondii. Belo Horizonte, UFMG, 1992. Tese (Doutorado) - Instituto de Ciências Biológicas, Universidade Federal de Minas Gerais.

09 - VOLLER, A.; BIDWELL. D.E.; BARTHTT. A. Enzyme immunoassay in diagnostic medicine. Theory and practice. Bulletin of the World Health Organization. v.53. p.55-65, 1976.

Recebido para publicação em $02 / 09 / 93$ Aprovado para publicação em 05/04/94 